\title{
Cloud Computing Support to University Business Processes in External Collaboration
}

\author{
Imre Petkovics ${ }^{1}$, Pere Tumbas ${ }^{1}$, Predrag Matković ${ }^{1}$, Zoltan \\ Baracskai $^{2}$ \\ ${ }^{1}$ University of Novi Sad, Faculty of Economics Subotica, Department of Business \\ Informatics, Segedinski put 9-11, 24000 Subotica, Serbia \\ e-mail: peti@ef.uns.ac.rs,ptumbas@ef.uns.ac.rs,pedja@ef.uns.ac.rs \\ ${ }^{2}$ Doctus Co. Csikihegyek út 8, 1118 Budapest, Hungary \\ e-mail: zoltan@doctus.hu
}

\begin{abstract}
Implementation of the business process management concept at universities has crucially contributed to abandoning traditional and introducing innovative processes in recent years. In particular, information technologies serve as not only means of automation but also a method of altering the approach to conducting business operations. Information technologies either facilitate or hinder the use faster, better and more cost-effective solutions for implementing business processes. This article analyses the possibility of supporting business processes in universities' external collaboration with cloud computing technologies, and their influence on the process' input-output data quality dimensions.
\end{abstract}

Keywords: cloud computing; business process; innovative university

\section{Introduction}

Information technologies (IT) have featured as a key factor in the implementation of the business process redesign (BPR) concept ever since its advent. They have been changing the nature of business processes, and this will continue in the future as well. The motives for the application of this radical concept in process redesigning in the organisation have been diverse, and the most common ones include the need to accelerate process implementation, reduce required resources, improve productivity and efficiency, and improve the organisation's competitiveness. Information technologies were originally used for accelerating and facilitating office work, rather than changing or transforming them [1]. However, BPR and IT have the potential to create more flexible, team oriented, coordinative and communication-based work capability [2]. Information technologies represent much more than a process automation toolkit. They enable full-scale reformation and redesign of a process. Researching the logical and 
natural relation between BPR and IT has not yet been fully completed [3] Information technologies are the most effective enabling technologies for BPR, aiding the accomplishment of redesign objectives in three ways: by providing information across functional levels and establishing easy communication, improving the process performance, and helping reengineering effort by modelling, optimizing and assessing its consequences [1].

Over the past decade, business processes at universities have also been changing and acquiring characteristics in accordance with changes occurring in higher education systems. Faced with challenges and dilemmas such as: globalisation vs. national needs, government administration vs. institutional autonomy, harmonisation vs. diversity, public vs. private sectors, basic vs. applied research, and competition vs. cooperation [4], universities respond by selecting and changing their processes. Thus, in their development, they undergo transformations through various organisation models, the most common being the Entrepreneurial University or the Innovative University model.

An Innovative University is a university of the entrepreneurial type, which is characterized by scientific and educational activities based on innovative technologies and principles of management [5]. The creation and implementation of innovation is the main goal and main content of the innovative activities. The system of innovative activities includes not only the development and creation of innovations but also the management of the innovative processes and the provision of conditions for their successful implementation [5].

Innovation at universities implies a need for them to reconsider their role and position in at least three areas, and define their own place in the contemporary higher education system development trends. These include areas of innovative teaching and learning process, innovative research process and enabling processes or organisational innovation processes.

The key factors for becoming an innovative university are most commonly structured in four categories: regulations and policies, external relations, internal stakeholders and infrastructure [6]. In particular, in the infrastructure category, the following IT infrastructure elements should be highlighted:

- reliable, fast and free internet connection, including wireless service;

- current software packages and use of open source software;

- well equipped classrooms, labs and libraries with digital boards, video projectors, etc.;

- sufficient available computers for all students;

- access to communication networks, and

- access to databases, online libraries, and online academic journals.

The research in this article is guided by the following research question: What is the supporting capability of cloud computing technologies in conducting universities' business processes in terms of improving universities' external 
collaboration? Seeking an answer to this question implied elaborating the concept, main characteristics, models of cloud computing technology and their advantages and disadvantages. This was followed by identifying and analysing universities' business processes from the aspect of input-output quality dimensions. Particular attention was devoted to analysing the quality of data that are consumed and produced by the identified processes. At the end of this research, conclusions were drawn on the possibility of applying particular types of service models and types of cloud computing technologies in the conduct of the universities' external collaboration and support of various innovation processes.

The following research hypotheses were set in the paper:

H1. Cloud computing technology improves university business processes.

H2. Integrated (Hybrid) cloud computing is the best way to implement information technology.

H3. Cloud computing technology contributes to the development of the Triple Helix concept of innovation through external collaboration.

H4. Applying cloud computing technology in performing universities' collaborative processes influences their input-output quality dimensions.

\section{Research Background}

\subsection{Cloud Computing - Definitions, Features, and Models}

Cloud computing concept broadly refers to using computer resources (hardware, software, platform, database servers, application, software packages etc.) over a network (the Internet) and for a vast majority of those involved in service-level understanding of the processing and payment [7].

The originator of the idea of cloud computing is John McCharty. He does not actually use the term "cloud computing" by concept formulation, but as computing utility, to denote the new paradigm. He argued that, in the future, computer timesharing technology might result in the fact that computing power and even specific applications could be sold through the utility business model [8].

The emergence of the Internet in 1969 relaunched the idea of computation services: "As of now, computer networks are still in their infancy. But as they grow up and become more sophisticated, we will probably see the spread of 'computer utilities' which, like present electric and telephone utilities, will service individual homes and offices across the country" [9][10]. We had to wait for almost fifty years to see his ideas realised. 
The word "cloud" itself was borrowed from the telephone companies, where the term "cloud" is applied to a situation where the contracted bandwidth is not specific wire pairs to deliver, but free phone lines activated at the time of the transfer to ensure guaranteed bandwidth. The word "cloud" is then applied to the state when it is still impossible to pinpoint the specific transmission lines.

The definition of cloud computing by the National Institute of Standards and Technology (NIST) reads as follows: "Cloud computing is a model for enabling ubiquitous, convenient, on-demand network access to a shared pool of configurable computing resources (e.g., networks, servers, storage, applications, and services) that can be rapidly provisioned and released with minimal management effort or service provider interaction" [11]. This definition primarily reflects the provider's point of view of cloud computing. The consumer side of cloud computing describes this phenomenon as a new cost-efficient computing paradigm in which applications, platforms, networks and computer power can be accessed from a Web browser by consumers without any information or care about the location of these resources, and all these resources/services are available on a pay-per-use basis. An academic definition of cloud computing was first given by Armbrust et al [12].

According to the NIST, cloud computing have five fundamental characteristics, involve three service models and four deployment models. The five main characteristics of cloud computing benefits are: (a) on-demand self-service, (b) ubiquitous, broad network access, (c) location-independent resource pooling, (d) rapid elasticity and (e) measured pay-per-use service.

Apart from the fundamental ones, there are some other significant features of cloud computing [7], [20]:

- Multitenancy - a single instance of an application serves multiple consumers (tenants) with the possibility (for the tenants) to customize some details (GUI or business rules) of the software applications;

- Identity management and access control - application of advanced techniques in identity checks and access control in order to provide legitimate data use;

- Security of services - implementation of the most stringent cutting-edge security measures for service provision;

- Increased reliability, because errors are constantly removed and repaired;

- Centralization of infrastructure and lower expenses of operation and maintenance;

- Diverse platform support, where cloud providers often provide services with built-in support for an abundant compilation of client platforms to reach a broader base of users;

- Faster development - cloud computing platforms with a large number of services and preset templates for application development considerably facilitate the development process.

NIST differentiates between three service models: 
1. Infrastructure as a Service (IaaS). IaaS is the lowest layer of cloud computing. At this level, the subject of service includes hardware resources (processor, memory, bandwidth and HDD storage) leased to the consumer. By means of leasing, consumers create the opportunity for installing and using virtual machines and various applications used in their business operations. The key advantages of IaaS for the consumer are:

- scalability - IaaS enables the consumer to simply lease additional resources for newly arisen needs on the pay-per-use principle; and

- portability - IaaS enables consumers to transfer their own virtual machines to some other hardware resources.

Iaas providers often mention the following advantages in their marketing activities as well: freedom from limits, power and control, predictability, expert guidance, cost savings, system acquisition bypass, enhanced agility and innovative business ricing.

2. Platform as a Service (PaaS). The NIST describes PaaS as "the capability provided to the consumer to deploy onto the cloud infrastructure consumercreated or acquired applications created using programming languages and tools supported by the provider." PaaS providers offer the consumers a development platform as a service, which they can use for their own software solution and deploy it on cloud infrastructure. In addition to the obligation to maintain hardware and replicate data, PaaS provider is responsible for managing operative systems, network resources, servers and storage, whereas the PaaS consumer is obliged to manage the deployed application and customise the application-hosting environment. Based on the above, it is obvious that $\mathrm{PaaS}$ is a higher layer of cloud computing in comparison with the IaaS. The advantages of PaaS for the consumer are:

- a development platform prepared for fine tuning and use - PaaS offers consumers platforms on which they can quickly develop and deploy their own software solutions; and

- consumers do not have to maintain hardware and network infrastructure; it is the PaaS that performs these tasks for consumers, so that the latter only need to perform their core activity - developing software solutions.

In addition to these key advantages, PaaS providers also point out reduced costs, faster time to market, lower development failure risk and increased security. Of course such a mode of cloud computing has its disadvantages as well, one of the most significant being the fact that PaaS providers demand that consumers sign long-term PaaS usage agreements.

3. Software as a Service (SaaS). SaaS is provision of software by providers to consumers on a pay-per-use service basis. The consumer uses the services for business purposes, through the Internet as a communication medium. While PaaS providers offer some kind of development platform, and IaaS provides infrastructure, SaaS offers any software solution uploaded to the cloud. SaaS 
providers may act as both IaaS or PaaS tenants and SaaS providers. By leasing SaaS, the consumer gets a complete and functional solution, with the only obligation to customize and use it, whereas the provider undertakes all other obligations. Such a way of meeting consumers' needs for software solutions frees the consumer from the obligation to buy software licenses and hardware required for the purchased licenses to function. The user benefits of SaaS are:

- pay-per-use - leasing the SaaS, the consumer pays the lease cost for a given time period, with a constantly open possibility to change the SaaS package;

- infrastructure maintenance and software updates - when leasing the SaaS, the consumer undertakes to configure and use the rented SaaS, and the provider undertakes all the obligations inherent to the lower IaaS Cloud layer, and the obligation to maintain and update the rented SaaS.

In addition to these key advantages, the SaaS providers also point out easier administration, compatibility, easier collaboration and global accessibility. The key disadvantage of SaaS is data lock-in, a problem most often manifested when attempting to transfer the service to another SaaS provider. The problem of data, i.e. their transferability, often emerges in such cases.

According to many sources [13], [14], [15] and [16] the list of the above services is not complete. There are many classifications of cloud computing services along different layers. Youseff et al. [16] were the first to suggest the presentation of cloud computing as a layered model with associated services. The new services on this model are:

1. Data Storage as a Service (DaaS). This is on-demand data storage that allows consumer to store their data via the Internet on remote disks and access them anytime from any place with any Internet accessible devices.

2. Communication as a Service (CaaS). This service provides communication encryption, network monitoring, dedicated bandwidth, guaranteed message delay, virtual overlays for traffic isolation, etc. (VoIP, audio conferencing and video conferencing) [17]

3. Hardware as a Service (HaaS). This is an on-demand data centre that includes the actual physical hardware and switches that form the backbone of the cloud by means of clusterisation.

From the aspect of deployment of Cloud Computing there are three (not exclusive) classifications, which are based on: (a) publicity of usage, (b) locality of realization and (c) organization of maintenance [17].

From the aspect of publicity of usage, the deployment models are:

- Private cloud: The cloud infrastructure is dedicated for exclusive use to a single organization with a large number of workers/end users.

- Community cloud: The type of cloud service that provides for a specific group of persons or organizations with common interest. 
- Public cloud: The type of cloud deployment that provides offer to any consumer for open use over the public Internet.

- Hybrid cloud: This design of cloud deployments present the mix or composition of two or three types of cloud deployment models (private, community, or public).

Some sources mention new deployment model forms, such as consumer cloud (like Facebook), although it is a typical form of public cloud, or government cloud (in the USA and South Korea), to emphasise the higher level of quality and innovation in retail service [18].

From the point of view of locality of implementation, the deployment models are [19]:

- Internal cloud, where services are offered by an internal IT organization (inhouse implementation) for internal usage (usually) (in-house computer clouds, physically located within organisation premises and protected by the organisation's firewall), where access is provided through the intranet, and the clouds are for internal use only;

- External cloud, where cloud computing services are not hosted by an internal IT organization (external implementation). An external cloud can be public or private, but must be implemented by an external IT organization (external computer clouds organised outside the user organised organisation by the cloud provider within its ecosystem).

From the aspect of organisation of maintenance, the deployment models are:

- in-house maintenance of cloud computing services, and

- outsourced maintenance of cloud computing services.

The emergence of cloud computing, of course, would have been impossible without the discovery of the Internet and a whole range of innovation and other technical and organisational novelties in the area of hardware miniaturisation, with a drastic decrease of energy consumption for work. On the other hand, the financial crisis lasting more than five years already gives rise to and dictates huge cost-cutting campaigns (i.e. severe cost limitations) in corporate functioning. The companies, therefore, do not invest major funds in IT nowadays (apart from PCs, laptops, notebooks or smart phones), but rather, when they need a more intense data processing environment, they opt for applying cloud computing rather than purchasing.

\subsection{Business Process Redesign - Concept and Process Quality}

BPR is a management technique applied for transforming organizations radically in order to improve them radically [22], [23]. According to most authors, the critical role in change initialisation is played by information technologies. As stated above, the IT infrastructure helps organisations not only automate business process activities, but also reshape and redesign business processes [24]. 
The primary features of BPR include: complete process redesign by means of radical change, with high risk and long implementation period where collaboration between business and IT is optional. The BPR process is cost-intensive, and the outcome is a drastic change in one or several business processes.

In order to meet consumer demands, companies have to design business processes in an appropriate way [21]. In particular, four essential process competencies feature as a basis for consideration, i.e. discussion: process cost, process flow time, process flexibility, and process quality [25]. It is essential to point out that the quality dimension of a process is often neglected in business process modelling and design. Normally, process quality has two groups of dimensions: the function quality dimensions and input-output quality dimensions.

A function is a basic building block in a business process that corresponds to an activity (task, process step) which needs to be executed [22]. Heravizadeh et al. identified thirteen quality dimensions, which can be relevant for a function, but not all are applicable for every function. These are: suitability, accuracy, security, reliability, understandability, learnability, time efficiency, resource utilisation, effectiveness, productivity, safety, user satisfaction and robustness [21]. Using these dimensions, analysts can identify quality aspects of particular functions of an individual process very precisely.

Table 1

Input output data quality dimensions

\begin{tabular}{|c|c|}
\hline $\begin{array}{r}\text { Input-output quality } \\
\text { dimensions }\end{array}$ & Description \\
\hline Accessibility & $\begin{array}{l}\text { Data accessibility refers to the extent to which data is easily } \\
\text { accessible (obtainable) when needed. }\end{array}$ \\
\hline Amount of data & Amount of data relates to a sufficient data volume for our needs. \\
\hline Completeness & $\begin{array}{l}\text { Completeness is the extent to which the data includes all } \\
\text { necessary values. }\end{array}$ \\
\hline Comprehensiveness & $\begin{array}{l}\text { Data comprehensiveness - means that all the required data } \\
\text { elements are included or that the record is complete. }\end{array}$ \\
\hline Consistency & $\begin{array}{l}\text { Data consistency - means that the data are reliable. } \\
\text { Data consistency is the synchronization of data objects across the } \\
\text { company. }\end{array}$ \\
\hline Currency & $\begin{array}{l}\text { Data currency/data timeliness - means that data should be up-to- } \\
\text { date and recorded at or near the time of the event or observation. }\end{array}$ \\
\hline Reliability & $\begin{array}{l}\text { Data should reflect stable and consistent data collection processes } \\
\text { across collection points and over time. }\end{array}$ \\
\hline Security & $\begin{array}{l}\text { Data security is the extent to which data is protected against } \\
\text { unauthorized access. }\end{array}$ \\
\hline Timeliness & $\begin{array}{l}\text { Data timeliness refers to the extent to which the data is } \\
\text { sufficiently current. }\end{array}$ \\
\hline Transparency & $\begin{array}{l}\text { Data transparency is the ability to trace back data to its origin and } \\
\text { find out its real world meaning. }\end{array}$ \\
\hline
\end{tabular}

The input and output of functions within a business process include physical and informational objects that are consumed and produced by it. Given the research subject, individual attention was devoted solely to data and information quality. 
Two categories of data quality are identified in [26] - data product quality and data service quality. Data product quality includes the quality aspects related to data itself, whereas service quality includes aspects related to the service delivery process of the information to consumers. Data quality attributes identified in [27], and modified in [21] make the focus of this research. A detailed analysis shortlisted ten out of twenty quality dimensions in correlation with cloud computing technology. A list of those and a brief description is given in Table 1 . The chosen data quality dimensions were used for assessing the eligibility of universities' collaborative business processes for the implementation of cloud computing technology.

\section{Research Methodology}

The basis for the analysis of university business processes was the „Project Task of Implementation of a Unified Information System of the University of Novi Sad", completed within the Tempus project "Governance and Management Reform in Higher Education in Serbia" (GOMES) in 2009. The project included identification of business processes of Serbian universities, which were then redesigned based on the experiences of partner universities from the EU (Italy, Greece, Poland, and Czech Republic) in business process implementation.

In view of the research question formulated in the article, the key activity in the remaining part of the research is gathering and analysing reference literature, which provides the overview of existing knowledge on the subject issue. For this reason, a comprehensive study of literature was carried out, followed by a detailed and rigorous verification of its validity and reliability. To provide transparency and repeatability of the entire procedure, the authors made a meticulous selection of academic databases, types of publication, key words and time interval.

The following academic bases were chosen for the purpose of this research: EBSCO Academic Search Premier, EBSCO Business Source Premier, Directory of Open Access Journals, Emerald Group Publishing, Science Direct and Wiley InterScience. Peer reviewed articles published in academic journals and proceedings of the scientific conferences from 2008 till 2013 were searched in them. The following search strings: "cloud computing", "cloud", "education" and "university" - in various combinations - were used in the search. They were searched in article titles, abstracts, and keywords. The results of research are presented in Table 2 and Table 3. 
Table 2

Search results for search strings "cloud computing", "cloud computing"+education, and "cloud computing"+university

\begin{tabular}{|c|l|c|c|c|c|c|c|}
\hline \multirow{2}{*}{$\begin{array}{c}\text { Academic } \\
\text { database }\end{array}$} & \multicolumn{1}{|c|}{ Provider } & \multicolumn{2}{|c|}{$\begin{array}{c}\text { "cloud } \\
\text { computing" }\end{array}$} & \multicolumn{2}{c|}{$\begin{array}{c}\text { "cloud } \\
\text { computing" + } \\
\text { education }\end{array}$} & \multicolumn{2}{c|}{$\begin{array}{c}\text { "cloud } \\
\text { computing" + } \\
\text { university }\end{array}$} \\
\cline { 2 - 8 } & & Title & Abstr & Title & Abstr & Title & Abstr \\
\hline $\begin{array}{c}\text { Academic Search } \\
\text { Premier, } \\
\text { Business Source } \\
\text { Premier }\end{array}$ & $\begin{array}{l}\text { EBSCO } \\
\text { publishing }\end{array}$ & 226 & 691 & 4 & 37 & 0 & 38 \\
\hline $\begin{array}{c}\text { Directory of Open } \\
\text { Access Journals }\end{array}$ & Lund University & 407 & 709 & 5 & 34 & 0 & 15 \\
\hline $\begin{array}{c}\text { Emerald Group } \\
\text { Publishing }\end{array}$ & $\begin{array}{l}\text { Emerald Group } \\
\text { Publishing }\end{array}$ & 7 & 21 & 0 & 3 & 0 & 1 \\
\hline Science Direct & Elsevier & 143 & 566 & 2 & 8 & 0 & 11 \\
\hline $\begin{array}{c}\text { Wiley } \\
\text { InterScience }\end{array}$ & $\begin{array}{l}\text { Wiley and } \\
\text { Blackwell }\end{array}$ & 54 & 717 & 0 & 6 & 0 & 4 \\
\hline
\end{tabular}

After a detailed analysis of search results, due to the multidisciplinary character of a large number of matches containing the key word "cloud" in Table 3, these were eliminated from further consideration.

A total of 1005 papers were downloaded, and 114 papers related to the research objective were selected after detailed examination. 88 of these were from scientific journals, and 26 from proceedings of scientific conferences. The dispersion of academic scientific journals where the papers were published is very large.

Table 3

Search results for search strings "cloud", "cloud+education", and "cloud+university"

\begin{tabular}{|r|l|c|c|c|c|c|c|}
\hline \multirow{2}{*}{$\begin{array}{c}\text { Academic } \\
\text { database }\end{array}$} & \multicolumn{1}{|c|}{ Provider } & \multicolumn{2}{|c|}{ cloud } & \multicolumn{2}{c|}{$\begin{array}{c}\text { cloud + } \\
\text { education }\end{array}$} & \multicolumn{2}{c|}{$\begin{array}{c}\text { cloud + } \\
\text { university }\end{array}$} \\
\cline { 3 - 8 } & Title & Abstr & Title & Abstr & Title & Abstr \\
\hline $\begin{array}{c}\text { Academic } \\
\text { Search } \\
\text { Premier, } \\
\text { Business }\end{array}$ & $\begin{array}{l}\text { EBSCO } \\
\text { publishing }\end{array}$ & 4652 & 13629 & 11 & 117 & 7 & 240 \\
\hline $\begin{array}{r}\text { Source Premier } \\
\text { Directory of } \\
\text { Open Access } \\
\text { Journals }\end{array}$ & Lund University & 1593 & 3759 & 12 & 48 & 0 & 65 \\
\hline $\begin{array}{r}\text { Emerald Group } \\
\text { Publishing }\end{array}$ & $\begin{array}{l}\text { Emerald Group } \\
\text { Publishing }\end{array}$ & 78 & 143 & 0 & 7 & 1 & 4 \\
\hline Science Direct & Elsevier & 1357 & 4308 & 5 & 17 & 0 & 53 \\
\hline $\begin{array}{r}\text { Wiley } \\
\text { InterScience }\end{array}$ & $\begin{array}{l}\text { Wiley and } \\
\text { Blackwell }\end{array}$ & 1680 & 4511 & 0 & 13 & 1 & 46 \\
\hline
\end{tabular}




\section{The Research Results}

According to the research elaborated in the Project task [28], the university business process model hierarchy comprises five hierarchy levels: mega processes, major processes, sub-processes, activities and tasks [31]. The highest level processes identified by the university are following mega processes: the learning and teaching process, the research process, the enabling process, and the planning and governance process. Table 4 gives an overall review of identified major processes, but only the sub-processes and activities possessing the innovative and collaborative component were selected and included in the analysis of possible support by cloud computing technologies.

Innovation with elements of entrepreneurship in university processes has been the subject of consideration over the past ten years. The characteristics most often highlighted in articles as the basis of innovation are: [5] [6] [30]

- international student education and student mobility including joint educational programmes;

- development of innovative education with using interdisciplinary, problemand project-oriented technologies;

- cooperation and collaboration between universities, business and government through the Triple Helix i.e. integration of scientific research and education;

- development of an infrastructure for interaction with the environment; and

- creation of a multi-channel financing system and appropriate university organisation and management structure.

Table 4

Overview of identified mega and major university business processes

\begin{tabular}{|l|l|}
\hline Learning and teaching process & Research process \\
\hline$\bullet$ study programme accreditation & $\bullet$ research planning \\
\hline$\bullet$ teaching process preparation and realisation & $\bullet$ research preparation \\
\hline$\bullet$ teaching process outcomes monitoring & $\bullet$ research conduct \\
\hline$\bullet$ teaching process assessment & $\bullet$ research outcomes monitoring \\
\hline$\bullet$ student and teacher mobility realisation & $\bullet$ research evaluation \\
\hline Enabling processes & Planning and governance processes \\
\hline$\bullet$ student administration services & $\bullet$ organisation management services \\
\hline$\bullet$ library services & $\bullet$ change and business process management \\
\hline$\bullet$ staff provision and development services & $\bullet$ plan development \\
\hline$\bullet$ finance and accounting services & $\bullet$ budget and funds planning \\
\hline$\bullet$ marketing, sale and distribution services & $\bullet$ performance assessment \\
\hline$\bullet$ procurement services & \\
\hline
\end{tabular}

In the evolution of universities from traditional to innovative, their openness is one of the most significant elements of development. Survival and progress of the university as a self-governing and independent organisation is absolutely inconceivable nowadays. The university's business processes are the driving force 
of innovation, especially processes extending beyond its organisational boundaries. Through these processes, universities collaborate with the environment, stimulating not only their own development, but also the development of society as a whole.

From the technical point of view, cloud computing is a technology usually deployed in the resources in a cloud, technologically ready to support the multitenancy principle. Such a technology facilitates collaboration in comparison with other technologies as one of its key characteristics. Collaboration is the reason for cloud computing being a technology that provides high-quality support to the conduct of universities' business processes reaching beyond its boundaries. Such processes are identified and analysed, and the applicability of cloud computing technology in their implementation is elaborated in the following section.

\section{Student and Teacher Mobility Realisation}

Realising student and teacher mobility is one of the identified major processes in the learning and teaching mega process, in which students attend a part of their study programmes outside their home universities, at other universities, usually outside the country where the headquarters of the home university seat is, whereas teachers go to other universities to perform teaching activities.

Although student and teacher mobility is an intrinsically open process, it is performed as a set of closed activities during its implementation. Only by integrating the activities into a single unified process does it acquire sense, of course, devoid of all the benefits that could be reached by opening its constituents. The analysis of the input-output quality dimensions of the student and teacher mobility process points to the possible benefits achievable by deploying the process into a cloud. Given the significance of the segments of this process in the universities' functioning, the following section is devoted to student mobility only.

The following data categories are used and created through student mobility programmes: data on universities, data on the programmes and courses available to students participating in the mobility process, data on teachers, data on students participating in the mobility process, data on mobility applications, data on learning agreements and data on students' academic performance.

Under the assumption of applying traditional computing, evaluating earlier categories of data from the viewpoint of defined input-output quality dimensions, the following characteristics improvable by means of cloud computing can be identified:

- Low accessibility: All the above mentioned data are on the university's internal resources, and therefore hard to access. Many of the data are even exchanged as paper documents, which are subsequently recorded in the universities' information systems. 
- High limitation of data amount: The student mobility process uses and generates large amounts of data, originating from various sources, and highly heterogeneous by form. Traditional computing uses limited resources by its nature, so that it can be freely said that the limitation of data amount is high.

- Low completeness and comprehensiveness: Mobility process is realised through a set of completely closed activities integrated into a whole. Such a mode of work causes data fragmentation, different standards for data, and their difficult integration. Completeness and comprehensiveness of data is difficult to achieve in such a mode, and requires high skill levels of university administrative staff.

- Low consistency: Different standards at universities result in low consistency, so that very often the same data have completely different denotation at different universities, and, similarly, in different sections of the same process.

- Fuzzy currency: Currency of a great majority of the above mentioned data depends on the currency of universities, and one set of data is, by nature, of questionable currency. This set of data refers to achieved results in the exchange, which are, in most cases, distributed by traditional mailing systems, or, in the best scenario, by e-mail. The reason for this should be sought in the existence of various university systems and lack of any connection between them.

- Fuzzy timeliness: Although process organisation defines the rules affecting the timely availability of data, delays and bottlenecks are very common in the mobility process, thus slowing it down. It must be emphasised that the process is slowed down by the existence of rules, due to the nature of data, which are often distributed through classical media.

- Average transparency: Data from the exchange process mostly stay in university archives, excluding the data whose transparency is insisted on through the rules of the exchange, such as Erasmus rules. Technologically, even if the rules of the process demand, transparency is not easy to reach in traditional computing. In traditional computing, it is achieved by combining various technologies for overcoming the limitations of the basic technology.

In addition to the above, it is necessary to pay attention to input-output quality dimensions, whose characteristics must be maintained when introducing cloud computing technology:

- High reliability: Reliability is a dimension of data quality with a positive value in the student mobility process, and is reached by means of traditional security measures, applied in processes generating important documents.

- High security: Data used and created in the student mobility process are characterised by high-quality in terms of security. They are stored in internal university bases and are subject to standards that the domicile students' data are subject to. 
Such requirements can be met by using a hybrid cloud, by placing sensitive functionalities and data on a private cloud, and the remaining ones on the community cloud.

\section{Joint Study Programmes Preparation, Realisation and Monitoring}

This is a special set of sub-processes from major processes in learning and teaching mega process. Joint study programmes are programmes prepared, conducted and evaluated by two or more universities. The outcome of joint programmes can be a joint degree or a double degree. What is characteristic of joint programmes is the participation of teachers from two or more universities in the conduct of a study programme, which is joint property of two or more universities. Sub-processes related to joint study programmes include: joint programme preparation and realisation, and joint programme monitoring.

The following groups of data are used and/or created when conducting joint study programmes: data on the study programme, data on courses, data on student workload, data on teachers, data on students, data on institutions, data on students' progress and data on degrees received.

Under the assumption of using traditional computing, the following characteristics of the data categories can be identified, from the standpoint of defined inputoutput quality dimensions, which can be enhanced by means of cloud computing:

- Low accessibility: Only one part of data is located on a university's internal resources, and other data cannot be accessed in real time. Data are often exchanged as paper documents or electronically.

- High limitation of data amount: like in the mobility process, a large amount of data is generated and stored on the limited resources of traditional computing.

- Low completeness and comprehensiveness: This process is accomplished through a set of completely closed activities integrated into a whole. Such a mode of work causes data fragmentation, different standards for data, and their difficult integration. Like in the case of student mobility process, completeness and comprehensiveness of data is difficult to achieve in such a mode, and requires high skill levels of university administrative staff.

- Low consistency: As joint study programmes are conducted at several universities as a rule, their different standards result in low consistency, so that very often the same data have completely different denotation at different universities, and, similarly, in different sections of the same process.

- High transparency: Like in the case of the mobility process, transparency in this process is also achieved by combining various technologies overcoming the limitations of traditional technologies. The joint programmes process is a rigidly formalised one, and, as such, demands high transparency of data. Any different characteristic of this quality dimension could compromise the entire process. However, efforts invested in attaining transparency in traditional computing can be significantly reduced for this process by using cloud computing. 
- Fuzzy currency: Analysis of timeliness of data points to a group of data which must be current: data on the study programme, data on courses, data on student workload, data on teachers, data on students, data on institutions, data on students' progress and data on degrees received. Similarly to the student mobility process, data on students' progress are often not current and relevant due to the existence of various university systems and lack of connection between them.

- Fuzzy timeliness: Data timeliness for most identified data groups is high, except for the data group related to student progress. Problems with timeliness mostly occur at the completion of studies, when it is necessary to record all the data at a unified place.

In addition to the above, it is necessary to pay attention to input-output quality dimensions, whose characteristics must be maintained when introducing cloud computing technology:

- High reliability and security: reliability and security are quality dimensions to which high degree of attention is devoted in traditional computing. As already stated in the description of these quality dimensions, data for student mobility process are stored in internal university bases and are subject to standards to which the data of each of the university's domicile study programmes are subject to. In the case of joint programmes, the positive assessment of these quality dimensions is further strengthened by data consolidation.

\section{Joint Research Planning, Preparation, Realisation, Monitoring and Evaluation}

This is a special set of sub-processes from major processes in research mega process. The research process is a process comprised of the following major processes: research planning, research preparation, research conduct, monitoring research outcomes and research evaluation. If the research process is viewed in the context of the universities' external collaboration, then it pertains solely to joint research. Joint research is research between universities and entities belonging to any of the elements of the Triple Helix (industry, government, intermediary). The research is conducted as research subsidised by national and international research support funds, commissioned by a corporate entity interested in using the research results, and the research initiated to develop the researcher's own resources.

Any form of research includes the following data classes: data on calls for proposals, data on researchers, data on funds, data on research institutions and data on research outcomes. The analysis of characteristics of the identified data categories was conducted for the joint research process as well, from the standpoint of earlier defined input-output quality dimensions, under the assumption of applying traditional computing:

- Low accessibility: although this is an open process, except in the case of commissioned research, traditional technologies make a negative impact on 
data accessibility. This is of particular interest for data that should be available when establishing research partnerships. Cloud computing technology creates predispositions not only for significant enhancement of accessibility, but also for managing it depending on the type of research.

- High limitation of data amount: quite identically as in the above discussed processes, the very nature of traditional computing and limitations of its resources produces high limitation of data amount.

- Low completeness and comprehensiveness: considering the nature of the research process itself, completeness and comprehensives feature as a vital requirement. Still, traditional computing makes a negative impact on the completeness and comprehensiveness of data, and very often results in their fragmentation and difficult integration.

- Average consistency: the consistency of the data used and/or created in the joint research process should be highly consistent. Harmonising the standards at the level of European Research Area raised the consistency of data to a much higher level than earlier. Still, traditional technologies often disrupt data consistency, due to implementation of local criteria and their subsequent harmonisation with the standards of the European Research Area.

- Fuzzy transparency: some of the data classes in the joint research process are characterised by high transparency, whereas some (mostly data on current research) demand low transparency. Still, traditional computing negatively affects the transparency of data classes for which a high value of this dimension is extremely important.

- Average currency and timeliness: in an ideal process realisation, data classes of the research process should be highly current and timely. However, although the research process by its nature implies current and timely data, still, in the real world, technological limitations of traditional computing result in the diminishment of these quality dimensions.

Like in the previously described processes, it is necessary to pay attention to input-output quality dimensions, whose characteristics must be retained when introducing cloud computing technology:

- High reliability and security: similar to the previous processes, the joint research conducted using traditional computing results in attaining high reliability and security. Conducting the process using cloud computing will tend to diminish it, and all technological measures must be taken in order to keep these dimensions on a high level.

Having considered the input-output quality dimensions of universities' collaborative processes based on traditional computing, Table 5 shows the influence of cloud computing on the same dimensions. The dark arrow represents an increase or decrease in the observed input-output quality dimension for all data classes, whereas a blank arrow represents a slight increase or reduction of the observed input-output quality dimensions of some or all data classes. 
In addition to the above described business processes of universities' external collaboration, it is also necessary to mention the collaborative processes through which universities joins various networks such as business, professional, alumni or social networks. At the same time, one must also mention collaboration conducted through the membership of universities in various associations (business, professional, expert, and general).

Table 5

The impact of cloud computing on input-output quality dimensions of universities' processes

\begin{tabular}{|c|c|c|c|c|c|c|c|c|c|c|c|}
\hline Processes & $\begin{array}{c}\text { Technology for } \\
\text { process } \\
\text { implementation }\end{array}$ & 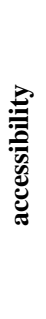 & 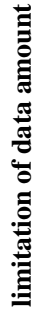 & 窇 & 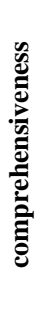 & 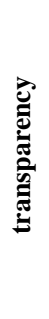 & 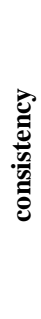 & 氖 & : & 尝 & : \\
\hline \multirow{2}{*}{$\begin{array}{c}\text { Student and } \\
\text { teacher } \\
\text { mobility } \\
\text { realisation }\end{array}$} & $\begin{array}{l}\text { traditional } \\
\text { computing }\end{array}$ & $\mathrm{L}$ & $\mathrm{H}$ & $\mathrm{L}$ & $\mathrm{L}$ & M & $\mathrm{L}$ & $\mathrm{F}$ & $\mathrm{F}$ & $\mathrm{H}$ & $\mathrm{H}$ \\
\hline & cloud computing & - & $\vartheta$ & - & -1 & - & 1 & $\widehat{\vartheta}$ & 仓 & $\sqrt{t}$ & $\sqrt{7}$ \\
\hline \multirow{2}{*}{$\begin{array}{l}\text { Joint study } \\
\text { programmes } \\
\text { preparation, } \\
\text { realisation and } \\
\text { monitoring }\end{array}$} & $\begin{array}{l}\text { traditional } \\
\text { computing }\end{array}$ & $\mathrm{L}$ & $\mathrm{H}$ & $\mathrm{L}$ & $\mathrm{L}$ & $\mathrm{H}$ & $\mathrm{L}$ & $\mathrm{F}$ & $\mathrm{F}$ & $\mathrm{H}$ & $\mathrm{H}$ \\
\hline & cloud computing & - & 7 & 1 & -1 & $\hat{\imath}$ & 1 & $\hat{\imath}$ & $\hat{\imath}$ & 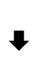 & 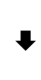 \\
\hline \multirow{2}{*}{$\begin{array}{l}\text { Joint research } \\
\text { planning, } \\
\text { preparation, } \\
\text { realisation, } \\
\text { monitoring and } \\
\text { evaluation }\end{array}$} & $\begin{array}{l}\text { traditional } \\
\text { computing }\end{array}$ & $\mathrm{L}$ & $\mathrm{H}$ & $\mathrm{L}$ & $\mathrm{L}$ & $\mathrm{F}$ & M & M & M & $\mathrm{H}$ & $\mathrm{H}$ \\
\hline & cloud computing & -1 & $\downarrow$ & -1 & 1 & $\hat{\imath}$ & 1 & 1 & -1 & 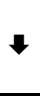 & 7 \\
\hline
\end{tabular}

Legend: L - Low, M -Medium, H - High, F - Fuzzy

\section{Conclusion}

The article proposes the use of cloud computing technologies, which, except in the case of relationships based on consulting and commercialisation foundations, significantly contribute to the attainment of expected outcomes in the universities' business processes. Given the specifics of the required data quality dimensions of certain processes at universities, such as the student and teacher mobility realisation, the joint study programmes preparation, realisation and monitoring, and the joint research planning, preparation, realisation, monitoring and evaluation, which it can fulfil, cloud computing technology is presented as 
successful in external collaboration processes. In particular, hybrid cloud imposes itself as the optimum solution for the implementation of cloud computing for such major processes at universities.

Cloud computing technology makes a significant impact on input-output data quality dimensions of universities' collaborative processes. This technology strongly increases accessibility, completness, comprehensiveness, consistency, and decreases limitation of data amount, reliability, and security. Also, cloud computing slightly increases currency, timeliness and transparency.

Cooperation and collaboration between universities, business i.e. industry, government and the community as a whole is a major plank in considering innovation systems. Stronger interactions and relationships between the Triple Helix entities should enhance their productivity, performance, and competitiveness. To this end, external collaboration must be formalised and enable knowledge transfer relationship in one of three relationship modes: market based contractual relationships, network based mutual relationships or integrated organisational relationships.

Implementing the cloud computing technology enables a more efficient and efficient execution of external cooperation and collaboration processes in developing a modern concept of innovative university. Furthermore, new possibilities are created in the modes of connecting the entities of the Triple Helix concept, i.e. academia, industry and government, which should provide universities with a changed status and key role in connecting the learning and teaching process with the research process.

\section{References}

[1] Attaran, M.: Exploring the Relationship between Information Technology and Business Process Reengineering, Information \& Management, 41(5), 2004, pp. 585-596

[2] Whitman, M. E.: IT Divergence in Reengineering Support: Performance Expectations vs. Perceptions, Information \& Management, 30(5), 1996, pp. $239-250$

[3] Grover, V., Jeong, S. R., Kettinger, W. J., Teng, J. T. C.: The Implementation of Business Process Reengineering, Journal of Management Information Systems, 12(1), 1995, pp. 109-144

[4] Guri-Rosenblit, S., Sebkova, H., Teichler, U.: Massification and Diversity of Higher Education System: Interplay of Complex Dimensions, Higher Education Policy, 20, 2007, pp. 373-389

[5] Berestova, T. V.: From Innovative Projects to an Innovative University, Scientific and Technical Information Processing, 36(3), 2009, pp. 180-185 
[6] Barluenga, M.: Becoming an Innovative University, $1^{\text {st }}$ Training Module: Strategic Implementation of University-Industry Cooperation, Universidad de Alicante, 2010

[7] Petkovics, I., Tumbas, P.: Temptation of the Past in the Shape of Clouds Cloud Computing, Conference Proceedings Informatika Korszerü Technikái IKT, Dunaújváros - Hungary, 2010, pp. 190-199

[8] Garfinkel, S. L.: The Cloud Imperative, MITTechnology Review Magazine, October, 2011

[9] Tugend, T.: UCLA to be First Station in Nationwide Computer Network. UCLA Press Realise, 1969

[10] Kleinrock, L.: A Tugend, T.: A Vision for the Internet, St. Journal of Research 2(1) Networked Multimedia, 2005, pp. 5-6

[11] Mell, P., Grance, T.: The NIST Definition of Cloud Computing, NIST Special Publication 800-145, September 2011

[12] Armbrust, M., et al.: Above the Clouds: A Berkeley View of Cloud Computing, Technical Report No. UCB/EECS-2009-28

[13] Naik, A. B., Ajay, A. K., Kolhatkar, S. S.: Applicability of Cloud Computing in Academia, Indian Journal of Computer Science and Engineering 4(1), 2013, pp. 11-15

[14] Leimeister, S., Böhm, M., Riedl, C., Krcmar, H.: The Business Perspective of Cloud Computing: Actors, Roles, and Value Networks, ECIS 2010 Proceedings, paper 56

[15] Böhm, M., Leimeister, S., Riedl, C., Krcmar, H.: Cloud Computing Outsourcing 2.0 or a new Business Model for IT Provisioning?, Application Management: Challenges - Service Creation - Strategies, Technische Universität München (TUM), Germany, 2011, pp. 31-56

[16] Youseff, L., Butrico, M., Da Silva, D.: Toward a Unified Ontology of Cloud Computing. Grid Computing Environments Workshop, 2008, pp. 110

[17] Petkovic, I.: CRM in the Cloud, Proceedings of the International Symposium on Intelligent Systems and Informatics, Subotica, Serbia, 2010

[18] Esayas, S. Y.: A Walk in to the Cloud and Cloudy it Remains: The Challenges and Prospects of 'Processing' and 'Transferring' Personal Data, Computer Law \& Security Review28(6), 2012, pp. 662-678

[19] Petkovič, I., Trninić, J., Đurković, J.: Information Technology Support of Sustainable Evolution, Proceeding of International Scientific Conference Strategic Management and Decision Support Systems in Strategic Management, Subotica-Palic, Serbia, 2013, pp. 447-460 
[20] Seres, L., Horvat, L., Horvat, I.: A Thunder in the Cloud, International Journal of Management Information Systems 6(1), 2011, pp. 16-19

[21] Heravizadeh, M., Mendling, J., Rosemann, M.: Dimensions of Business Processes Quality, In Business Process Management Workshops, Springer Berlin Heidelberg, pp. 16-19

[22] Hammer, M, Champy, J.: Reengineering the Corporation: a Manifesto for Business Revolution, McGraw Hill, New York, 1993

[23] Davenport, T. H.: Process Innovation: Reengineering Work Through Information Technology, Harvard Business School Press, Boston, 1993

[24] Bhatt, G. D.: Exploring the Relationship between Information Technology, Infrastructure and Business Process Re-Engineering, Business Process Management Journal 6(2), 2000, pp. 139-163

[25] Anupindi, R., Chopra, S., Deshmukh, S., Mieghem, J., Zemel, E.: Managing Business Process Flows. Prentice Hall, 1999

[26] Kahn, B., Strong, D., Wang, R.: Information Quality Benchmarks: Product and service performance. Communications of the ACM 45(4), 2002, pp. 184-192

[27] Wang, R. Y., Strong, D. M.: Beyond Accuracy: What Data Quality Means to Data Consumers. Journal of Management Information System 12(4), 1996, pp. 5-34

[28] Tumbas, P., Matkovic, P.: Projektni zadatak implementacije jedinstvenog informacionog sistema Univerziteta u Novom Sadu, Novi Sad, 2009

[29] Mircea, M., Andreescu, A. I.: Using Cloud Computing in Higher Education: A Strategy to Improve Agility in the Current Financial Crisis, Communications of the IBIMA 2011(32), 2011

[30] Christensen, C. M., Eyring, H. J.: The Innovative University, Jossey-Bass A Willey Imprint, San Francisco, 2011

[31] Tonchia, S., Tramontano, A.: Process Management for the Extended Enterprise, Springer-Verlag Berlin - Heidelberg, 2004 